\title{
Postprandial hyperaminoacidaemia overcomes insulin resistance of protein anabolism in men with type 2 diabetes
}

\author{
M. Bassil • E. B. Marliss • J. A. Morais • S. Pereira • \\ S. Chevalier $\cdot$ R. Gougeon
}

Received: 27 July 2010 / Accepted: 22 October 2010 / Published online: 26 November 2010

(C) Springer-Verlag 2010

\begin{abstract}
Aims/hypothesis Although protein is usually ignored when considering insulin resistance, we have shown resistance of protein concurrent with glucose metabolism in men with type 2 diabetes during a hyperinsulinaemic clamp at euglycaemia and fasting aminoacidaemia. We hypothesised that this resistance is even worse during conditions that simulate the postprandial state, when anabolism should be maximal.

Methods Eight overweight and obese men with type 2 diabetes underwent a hyperinsulinaemic-hyperglycaemic (8 mmol/l) clamp, first with plasma amino acids at postabsorptive (Hyper-2) then at postprandial concentrations (Hyper-3). Whole-body protein kinetics were assessed using L- $\left[1-{ }^{13} \mathrm{C}\right]$ leucine. Hyper-2 results were compared with those of diabetic men whose plasma glucose was lowered to $5.5 \mathrm{mmol} / \mathrm{l}$ and fasting aminoacidaemia maintained during the hyperinsulinaemic clamp (Hyper-1).

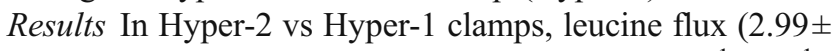
0.16 vs $2.62 \pm 0.06 \mu$ mol kg [fat-free mass (FFM) ${ }^{-1} \mathrm{~min}^{-1}$ ), rates of synthesis $(2.31 \pm 0.15$ vs $1.98 \pm 0.06)$ and breakdown $(2.38 \pm 0.16$ vs $2.00 \pm 0.07)$ were higher $(p<0.05)$, but leucine oxidation and net balance did not differ. In Hyper-3 vs Hyper-2 clamps, leucine flux and synthesis and oxidation rates increased markedly as did net balance $(0.84 \pm 0.09$ vs $\left.-0.07 \pm 0.04 \mu \mathrm{mol}[\mathrm{kg} \mathrm{FFM}]^{-1} \min ^{-1}, p<0.0001\right)$.

Conclusions/interpretation In type 2 diabetic men, insulin resistance of protein metabolism is of the same magnitude
\end{abstract}

M. Bassil • E. B. Marliss · J. A. Morais · S. Pereira •

S. Chevalier $\cdot$ R. Gougeon $(\bowtie)$

McGill University Nutrition and Food Science Centre,

McGill University Health Centre/Royal Victoria Hospital,

687 Pine Avenue West, H6.61,

Montreal, QC, Canada H3A 1A1

e-mail: rejeanne.gougeon@muhc.mcgill.ca at 8 vs $5.5 \mathrm{mmol} / \mathrm{l}$, but turnover rates are higher with hyperglycaemia. Contrary to our hypothesis, sustained postprandial-level hyperaminoacidaemia stimulated positive net protein balance comparable with that previously found in lean non-diabetic men. This was sufficient to overcome the insulin resistance of protein anabolism.

Keywords Fed state $\cdot$ Hyperaminoacidaemia .

Hyperinsulinaemic clamp · Insulin resistance $\cdot$ Leucine

kinetics $\cdot$ Protein metabolism Type 2 diabetes

$\begin{array}{ll}\text { Abbreviations } \\ \text { BCAA } & \text { Branched-chain amino acids } \\ \text { FFM } & \text { Fat-free mass } \\ \text { IAA } & \text { Indispensable amino acids } \\ \text { KIC } & \alpha \text {-Ketoisocaproic acid } \\ \text { LSD } & \text { Least significant difference } \\ R_{\mathrm{a}} & \text { Rate of appearance } \\ R_{\mathrm{d}} & \text { Rate of disappearance } \\ \text { REE } & \text { Resting energy expenditure } \\ \text { RQ } & \text { Respiratory quotient } \\ \text { TAA } & \text { Total amino acids }\end{array}$

Introduction

Abnormal protein metabolism is not widely recognised as part of the consequences of insulin resistance. Despite there being few clinical signs of abnormal protein metabolism in type 2 diabetes, we have demonstrated the presence of insulin resistance of protein metabolism in men [1]. Furthermore, a recent study of older men and women followed for 6 years showed that those with type 2 diabetes lost more appendicular lean body mass, and this was even 
more pronounced when diabetes was diagnosed only at study entry [2]. Type 2 diabetes was also associated with increased risk of sarcopenia in the Korean Sarcopenic Obesity Study [3].

Insulin stimulates protein synthesis and suppresses catabolism in vitro [4-7] and in vivo [8-10]. Amino acids, particularly the branched-chain amino acids (BCAA), have effects on protein synthesis that are both independent of $[11,12]$ and synergistic with insulin $[8,11,12]$. In order to dissect the effects of insulin from those of amino acids on whole-body protein metabolism, hyperinsulinaemic-euglycaemic clamps and isotopic tracer techniques have been used. Amino acids are infused to maintain fasting serum concentrations (isoaminoacidaemia) which otherwise fall because of insulin suppression of proteolysis [11, 13]. Using this 'Hyper-1 clamp', we have found blunted wholebody anabolic responses to insulin in overweight and obese men with poorly controlled type 2 diabetes. There was a significant association between insulin resistance of glucose and of protein metabolism [1]. Women with type 2 diabetes did not show added diabetes effects compared with overweight and obese controls [1], in whom we had reported insulin resistance of protein anabolism vs lean women and men [14]. This justifies why men only were studied in the present protocol. Of note is that during conventional hyperinsulinaemic clamps in type 2 diabetes [ 1 , 15-17], plasma glucose is decreased from hyperglycaemia and maintained at euglycaemia $(5.5 \mathrm{mmol} / \mathrm{l})$ in order to reproduce comparable conditions as in lean and obese controls. This could create an acute normalisation that may mask impairment associated with hyperglycaemia. For this reason, in the present study, plasma glucose was maintained at $8 \mathrm{mmol} / \mathrm{l}$ during a two-step hyperinsulinaemic clamp (Hyper-2/Hyper-3).

Under normal physiological conditions, the greatest protein anabolism occurs in the fed state, during which concentrations of insulin, glucose and amino acids are elevated and those of NEFA are low. Thus, insulin resistance of protein anabolism, if present, would be predicted to be maximal in this state. However, kinetic methods are most reliable during sustained steady states. We therefore developed the hyperinsulinaemic-hyperglycaemic-hyperaminoacidaemic (Hyper-3) technique with all concentrations clamped at peak values reached postprandially, thereby simulating a fed steady state [8]. This caused a marked increase in wholebody net protein accretion in healthy lean men during Hyper-3 compared with Hyper-1. There was an additive effect of raised amino acids to that of insulin [8]. Normal whole-body protein anabolic response to clamping insulin and amino acids at postprandial concentrations in type 2 diabetes was reported by Luzi et al. [17]. The study, however, included both sexes, and glucose was maintained at euglycaemia $(5.5 \mathrm{mmol} / \mathrm{l})$, which did not mimic fed-state concentrations. Similarly, another study showed that hyperglycaemic diabetic men have unaltered protein kinetics after ingesting boluses of carbohydrates and hydrolysed protein [18]. The total, taken in repeated boluses, being extremely large (268 g carbohydrates and $134 \mathrm{~g}$ protein) may, however, indicate that in type 2 diabetes, the protein anabolic capacity is maintained with generous protein intake.

The present study was designed to investigate the effect of hyperglycaemia on whole-body protein kinetics in type 2 diabetes during isoaminoacidaemia (Hyper-2 vs Hyper-1) and to quantify the effect of hyperaminoacidaemia during Hyper-3. Results have been presented in part in abstract form [19], and results of the Hyper-1 group are from eight individuals selected from a previous study [1] to match for body composition.

\section{Methods}

Sixteen white overweight and obese men (eight per protocol) aged $<65$ years, with conventionally controlled type 2 diabetes were studied (Table 1). Individuals were screened with fasting blood and urine samples, electrocardiograms, chest X-rays and a complete physical examination. Participants signed the study consent form approved by the institutional research ethics board. Exclusion criteria included smoking, unstable weight for the previous 6 months, insulin therapy, abnormal dietary habits assessed by $24 \mathrm{~h}$ dietary recall, significant hepatic, haematological, renal, pulmonary or cardiovascular dysfunction, and medications known to affect metabolism.

Individuals were admitted for 4 to 6 days to the McGill University Health Centre/Royal Victoria Hospital Clinical Investigation Unit. All participants except one were treated with oral antihyperglycaemic drugs: metformin, 13; sulfonylurea, 11; and repaglinide and a thiazolidinedione, one

Table 1 Participant characteristics

\begin{tabular}{llll}
\hline Characteristic & $\begin{array}{l}\text { Hyper-2/ } \\
\text { Hyper-3 }\end{array}$ & Hyper-1 & $p$ value \\
\hline$n$ & 8 & 8 & \\
Age (years) & $57 \pm 2$ & $55 \pm 2$ & 0.537 \\
Height $(\mathrm{cm})$ & $177.5 \pm 2.1$ & $177.5 \pm 1.9$ & 0.995 \\
Weight $(\mathrm{kg})$ & $107.7 \pm 7.3$ & $95.9 \pm 5.2$ & 0.206 \\
BMI $\left(\mathrm{kg} / \mathrm{m}^{2}\right)$ & $34.0 \pm 1.6$ & $30.3 \pm 1.3$ & 0.106 \\
FFM $(\mathrm{kg})$ & $71.7 \pm 3.9$ & $67.3 \pm 3.1$ & 0.393 \\
Body fat $(\%)$ & $34.9 \pm 2.2$ & $29.5 \pm 1.4$ & 0.187 \\
Waist circumference $(\mathrm{cm})$ & $118.6 \pm 4.8$ & $108.2 \pm 3.7$ & 0.108 \\
HbA 1 (\%) & $7.1 \pm 0.2$ & $7.0 \pm 0.3$ & 0.642 \\
Diabetes duration (years) & $9 \pm 2$ & $6 \pm 2$ & 0.233 \\
\hline
\end{tabular}

Data are means \pm SEM

FFM measured by bioimpedance analysis 
each. Eight individuals were treated with statins and nine with antihypertensive agents. All medications except antihypertensives were held on the clamp day until the end of the experiment. Participants consumed a formula-based (Ensure and Glucerna; Ross Laboratories, Montreal, QC, Canada) isoenergetic, protein controlled diet divided in five equal meals from 08:00 to 20:00 hours for 6 to 8 days. It provided $1.7 \mathrm{~g}$ protein $(\mathrm{kg} \text { fat-free mass }[\mathrm{FFM}])^{-1}$ day $^{-1}$ (15-16\% of energy), $59-60 \%$ of energy from carbohydrate and $25 \%$ from fat. Weight was maintained by calculating total energy expenditure based on resting energy expenditure (REE) (Deltatrac; SensorMedics, Yorba Linda, CA, USA), multiplied by $1.5-1.6$. An energy supplement [twothirds glucose polymer (Polycose; Abbott Laboratories, StLaurent, QC, Canada) and one-third vegetable oil] was given to correct for energy loss according to the preceding day's measured glycosuria. Participants' habitual daily physical activity, assessed using the MONICA Optional Study of Physical Activity (MOSPA) questionnaire [20], reflected a sedentary lifestyle. Prior to clamp studies, activity was limited for 6 to 8 days to short non-brisk walks. Circumferences (waist, hip, chest, calf and thigh) were measured according to World Health Organization 1995 criteria and body composition was determined by bioimpedance analysis for all individuals (RJL-101A Systems, Detroit, MI, USA) and by dual energy x-ray absorptiometry (Lunar Prodigy Advance; GE Healthcare, Madison, WI, USA) for Hyper-2/Hyper-3 participants in whom FFM measured by both methods did not differ significantly. Capillary glucose $>15 \mathrm{mmol} / \mathrm{l}$, measured before meals (Accuchek III; Boehringer Ingelheim, Mannheim, Germany) was treated with small doses of subcutaneous insulin except during the $15 \mathrm{~h}$ prior to the clamp.

On the clamp day (Fig. 1) at 08:00 hours, catheters were inserted in an antecubital vein for infusions and in the opposite hand for blood sampling. The hand was kept in a

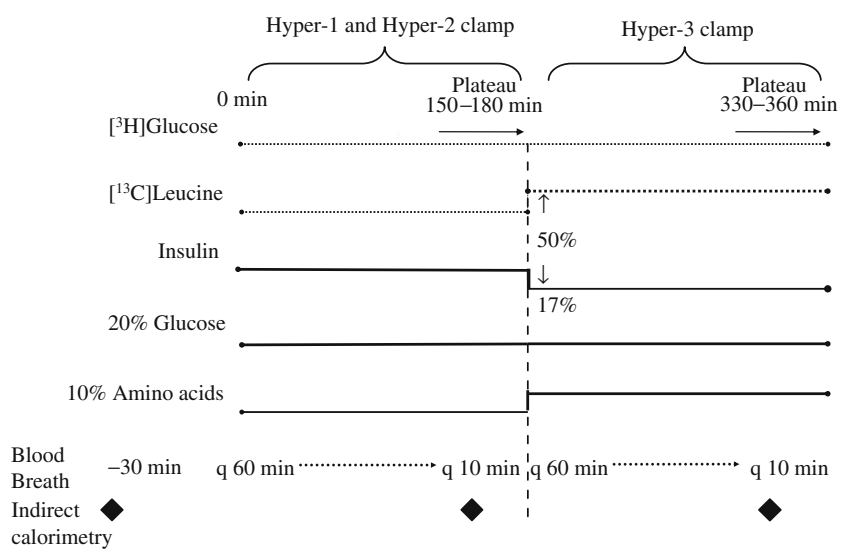

Fig. 1 Hyper-1 and Hyper-2 clamp protocols with postabsorptive aminoacidaemia. Hyper-2 only was followed by postprandial aminoacidaemia (Hyper-3) in men with type 2 diabetes mellitus heated box at $65-70^{\circ} \mathrm{C}$ to arterialise venous blood [21]. Then, a bolus of $0.1 \mathrm{mg} / \mathrm{kg}$ of oral $\mathrm{NaH}^{13} \mathrm{CO}_{2}$ (MassTrace, Woburn, MA, USA) and of $0.5 \mathrm{mg} / \mathrm{kg}$ of intravenous L$\left[1-{ }^{13} \mathrm{C}\right]$ leucine (Isotech; Sigma-Aldrich, St Louis, MO, USA) was given, followed by a constant infusion rate of $0.008 \mathrm{mgkg}^{-1} \mathrm{~min}^{-1}$ for leucine kinetic determination. A primed infusion of biosynthetic regular human insulin (Humulin R; Eli Lilly Canada, Toronto, ON, Canada) was given concurrently at $1.1 \mathrm{mU}(\mathrm{kg} \mathrm{FFM}){ }^{-1} \mathrm{~min}^{-1}$. Low ${ }^{13} \mathrm{C}$ enriched 20\% glucose in water (Avebe, Foxhol, the Netherlands) and an amino acid solution (TrophAmine $10 \%$ without electrolytes; B. Braun Medical, Irvine, CA, USA) (Table 2) were infused at variable rates to maintain constant concentrations based on plasma measurements of glucose and BCAA as indicator of total amino acids (TAA) at $5 \mathrm{~min}$ intervals. Glucose was clamped at $8 \mathrm{mmol} / \mathrm{l}$ in Hyper-2 and at $5.5 \mathrm{mmol} / \mathrm{l}$ in Hyper-1. Total BCAA were maintained at individual participants' fasting concentrations in both Hyper-2 and Hyper-1.

As depicted in Fig 1, $3 \mathrm{~h}$ after the start of insulin infusion, Hyper-2 was followed by Hyper-3 by increasing BCAA to $750 \mu \mathrm{mol} / \mathrm{l}$. Insulin, glucose and BCAA targets for Hyper-3 were obtained from peak postprandial concentrations reached during a meal test $(2981 \mathrm{~kJ}, 30 \mathrm{~g}$ protein) in lean healthy individuals (data not shown). The $\mathrm{L}-\left[1-{ }^{13} \mathrm{C}\right]$ leucine infusion

Table 2 TrophAmine amino acid composition

\begin{tabular}{lll}
\hline Amino acid & \multicolumn{2}{l}{ Amino acid composition } \\
\cline { 2 - 3 } & g per $100 \mathrm{ml}$ & $\mathrm{mmol} / 1$ \\
\hline Total & 10 & 765.0 \\
Essential amino acids & 5.28 & 390.1 \\
Isoleucine & 0.82 & 62.5 \\
Leucine & 1.4 & 106.7 \\
Lysine & 0.82 & 56.1 \\
Methionine & 0.34 & 22.8 \\
Phenylalanine & 0.48 & 29.1 \\
Threonine & 0.42 & 35.3 \\
Tryptophan & 0.2 & 9.8 \\
Valine & 0.78 & 66.6 \\
Non-essential amino acids & 4.7 & 374.9 \\
Alanine & 0.54 & 60.6 \\
Arginine & 1.2 & 68.9 \\
Proline & 0.68 & 59.1 \\
Serine & 0.38 & 36.2 \\
Glycine & 0.36 & 48.0 \\
L-Aspartic acid & 0.32 & 24.0 \\
L-Glutamic acid & 0.5 & 34.0 \\
Tyrosine & 0.24 & 13.2 \\
Histidine & 0.48 & 30.9 \\
Cysteine & 0.016 & 1.3 \\
\hline & & \\
& &
\end{tabular}


rate was increased by $50 \%$ to prevent dilution of isotopic enrichment by exogenous leucine, and the insulin infusion was decreased by $17 \%$ to correct for the stimulation of endogenous insulin secretion by increasing amino acid concentrations [22]. The Hyper-3 clamp lasted for $3 \mathrm{~h}$ after which all infusions were stopped. In the Hyper-1 study, the $3 \mathrm{~h}$ hyperinsulinaemic period followed $3 \mathrm{~h}$ of postabsorptive state with only tracer infusions (data not presented).

Steady states of glucose and amino acid concentrations and infusion rates were achieved within $120 \mathrm{~min}$ and maintained until $180 \mathrm{~min}$. Kinetics were calculated during the last $30 \mathrm{~min}$ ('plateau') of each phase of the clamps. Indirect calorimetry was performed for $20 \mathrm{~min}$ at baseline and during plateaus. Arterialised blood samples were collected for substrates, hormones and isotopic enrichment, at baseline and every hour until $50 \mathrm{~min}$ prior to end of the clamps, and thereafter at 10 min intervals. Simultaneously, expired air samples were collected in evacuated tubes for analysis of ${ }^{13} \mathrm{CO}_{2}$ enrichment (Becton Dickinson Vacutainer Systems, Franklin Lakes, NJ, USA).

$\mathrm{L}-\left[1-{ }^{13} \mathrm{C}\right]$ leucine kinetics were calculated according to Matthews et al. [23], using plasma $\left[1-{ }^{13} \mathrm{C}\right] \alpha$-ketoisocaproic acid (KIC) enrichment (reciprocal model) [24], providing leucine total rate of appearance ( $R_{\mathrm{a}}$ flux), endogenous $R_{\mathrm{a}}$ (protein breakdown), oxidation and non-oxidative endogenous rate of disappearance $\left(R_{\mathrm{d}}\right.$ protein synthesis). The ${ }^{13} \mathrm{C}$ enrichments of expired $\mathrm{CO}_{2}$ and $\dot{V} \mathrm{CO}_{2}$ from indirect calorimetry were used in calculating leucine oxidation. The recovery factor, the proportion of ${ }^{13} \mathrm{CO}_{2}$ generated during oxidation that is exhaled [23, 25], was 0.799 during Hyper-1 and Hyper-2 steady states and 0.824 for Hyper-3, based on previous bicarbonate studies done in our laboratory. In the calculation of leucine oxidation rates, correction was made to ${ }^{13} \mathrm{CO}_{2}$ enrichment because low- $\left[{ }^{13} \mathrm{C}\right]$ glucose solutions dilute the natural enrichment, as previously described by Chevalier et al. [26]. A factor of $7.0 \%$ was used as determined by additional clamp studies carried out in obese control individuals with or without type 2 diabetes during which L$\left[1-{ }^{13} \mathrm{C}\right]$ leucine was omitted.

Assays Enrichment of plasma $\left[{ }^{13} \mathrm{C}\right]-\alpha-\mathrm{KIC}$ was determined by GC-MS (5988A; Hewlett-Packard, Palo Alto, CA, USA) after derivatisation with $N$-methyl- $N$-(tert-butyldimethylsilyl) trifluoroacetamide (Regis Technologies, Morton Grove, IL, USA) as detailed previously by Chevalier et al. [27]. Expired ${ }^{13} \mathrm{CO}_{2}$ enrichment was measured by isotope ratio mass spectrometry (Vacuum Generators, Winsforce, UK), plasma glucose concentration by glucose oxidase (GM7 Micro-Stat; Analox Instruments USA, Lunenberg, MA, USA) and total BCAA during clamp, by an enzymatic fluorometric assay (FP-6200; Jasco Corporation, Tokyo, Japan). BCAA are oxidatively deaminated to their corresponding ketoacid, by leucine dehydrogenase in the presence of $\mathrm{NAD}^{+}$. NADH is generated stochiometrically; its fluorescence is measured at $4 \mathrm{~min}$ of the reaction, at $37^{\circ} \mathrm{C}, 355 \mathrm{~nm}$ excitation and $485 \mathrm{~nm}$ emission wavelengths [28]. Serum insulin, C-peptide and glucagon were determined by radioimmunoassay (Millipore, Billerica, MA, USA). Serum NEFA concentrations were measured by a colorimetric assay (NEFA C; Wako Chemicals USA, Richmond, VA, USA) and reverse-phase HPLC was used to determine individual plasma amino acid concentrations after pre-column derivatisation with $o$-phtalaldehyde [14].

Statistical analyses Results are presented as means \pm SEM. Repeated-measures ANOVA was used to assess clamp effects on kinetics, hormones and substrates for withinindividual (baseline vs Hyper-1, and baseline vs Hyper-2 vs Hyper-3, with least significant difference [LSD] post-hoc test) and between-individual responses to the clamp (Hyper-1 vs Hyper-2). Data comparisons between Hyper-1 and Hyper-2 clamp periods were made using independent $t$ tests. Pearson's coefficient was used for simple correlations between variables, and stepwise multiple regression to estimate the magnitude of variation that is explained by each variable. HOMA was non-normally distributed and hence log-transformed, and presented as $\log _{e}$ HOMAinsulin resistance (HOMA-IR). Based on a paired design [29] and SD from our previous results [8], a sample size of eight participants was needed to detect a $20 \%$ difference in protein synthesis rates between Hyper- 2 and Hyper-3 clamps, (one-tailed $\alpha=0.05, \beta=0.10$ ). Analyses were performed using SPSS17.0 for Windows (SPSS, Chicago, IL, USA).

\section{Results}

Age, height and $\mathrm{HbA}_{1 \mathrm{c}}$ were matched between participant groups. Mean weight, BMI, \% body fat and waist circumferences were non-significantly different (Table 1). Per cent body fat and waist circumferences of all individuals were above healthy reference values [30].

Baseline and clamp substrate, respiratory gas exchange and hormone concentrations are presented in Table 3. By design, participants were hyperglycaemic at baseline; glucose was decreased to $5.5 \mathrm{mmol} / \mathrm{l}$ during Hyper-1, and maintained at $8 \mathrm{mmol} / \mathrm{l}$ during Hyper-2 and Hyper-3. Compared with baseline, hyperinsulinaemia did not affect REE or respiratory quotient (RQ) during Hyper-2 but increased RQ in Hyper-1. Raising amino acids significantly increased REE without affecting RQ during Hyper-3. Fasting concentrations of TAA and indispensable amino acids (IAA) and BCAA were maintained during Hyper-1 and Hyper-2, but leucine concentrations during Hyper-2 increased slightly. Subsequently during Hyper-3, TAA were 
Table 3 REE, RQ and circulating substrate and hormone concentrations at baseline and during clamps
Data are means \pm SEM

Within the same row, values with different superscript letters are significantly different (paired $t$ test or repeated measures ANOVA and LSD post hoc test)

${ }^{*} p<0.05$ vs Hyper-1 clamp (independent $t$ test)

${ }^{\dagger}$ Significant group effect in response to clamp (repeatedmeasures ANOVA)

\begin{tabular}{|c|c|c|c|}
\hline \multirow[b]{2}{*}{ Variable and protocol } & \multirow[b]{2}{*}{ Baseline } & \multicolumn{2}{|l|}{ Hyperinsulinaemia } \\
\hline & & Isoaminoacidaemia & Hyperaminoacidaemia \\
\hline \multicolumn{4}{|l|}{$\operatorname{REE}(\mathrm{kJ} / \mathrm{min})$} \\
\hline Hyper-2/Hyper-3 & $6.1 \pm 0.3^{\mathrm{a}}$ & $6.1 \pm 0.3^{\mathrm{a}}$ & $6.4 \pm 0.3^{\mathrm{b}}$ \\
\hline Hyper-1 & $5.6 \pm 0.2$ & $5.6 \pm 0.3$ & \\
\hline \multicolumn{4}{|l|}{ RQ } \\
\hline Hyper-2/Hyper-3 & $0.80 \pm 0.02$ & $0.81 \pm 0.02$ & $0.81 \pm 0.02$ \\
\hline Hyper-1 & $0.79 \pm 0.02^{\mathrm{a}}$ & $0.85 \pm 0.02^{\mathrm{b}}$ & \\
\hline \multicolumn{4}{|l|}{ Glucose $(\mathrm{mmol} / / \mathrm{l})^{\dagger}$} \\
\hline Hyper-2/Hyper-3 & $8.38 \pm 0.61$ & $7.95 \pm 0.04^{*}$ & $7.93 \pm 0.02$ \\
\hline Hyper-1 & $8.75 \pm 0.62^{\mathrm{a}}$ & $5.51 \pm 0.03^{\mathrm{b}}$ & \\
\hline \multicolumn{4}{|l|}{ TAA $(\mu \mathrm{mol} / \mathrm{l})$} \\
\hline Hyper-2/Hyper-3 & $2499 \pm 95^{\mathrm{a}}$ & $2564 \pm 138^{\mathrm{a}}$ & $3381 \pm 182^{\mathrm{b}}$ \\
\hline Hyper-1 & $2669 \pm 47$ & $2531 \pm 37$ & \\
\hline \multicolumn{4}{|l|}{ IAA $(\mu \mathrm{mol} / \mathrm{l})$} \\
\hline Hyper-2/Hyper-3 & $966 \pm 51^{\mathrm{a}}$ & $1013 \pm 49^{\mathrm{a}}$ & $1548 \pm 66^{\mathrm{b}}$ \\
\hline Hyper-1 & $1012 \pm 22$ & $1005 \pm 20$ & \\
\hline \multicolumn{4}{|l|}{ BCAA $(\mu \mathrm{mol} / \mathrm{l})$} \\
\hline Hyper-2/Hyper-3 & $454 \pm 23^{\mathrm{a}}$ & $470 \pm 19^{\mathrm{a}}$ & $770 \pm 25^{\mathrm{b}}$ \\
\hline Hyper-1 & $451 \pm 19$ & $440 \pm 18$ & \\
\hline \multicolumn{4}{|l|}{ Leucine $(\mu \mathrm{mol} / \mathrm{l}) \dagger$} \\
\hline Hyper-2/Hyper-3 & $136 \pm 11^{\mathrm{a}}$ & $156 \pm 8^{b}$ & $312 \pm 14^{\mathrm{c}}$ \\
\hline Hyper-1 & $144 \pm 7$ & $146 \pm 7$ & \\
\hline \multicolumn{4}{|l|}{ NEFA $(\mu \mathrm{mol} / \mathrm{l})$} \\
\hline Hyper-2/Hyper-3 & $462 \pm 74^{\mathrm{a}}$ & $114 \pm 28^{\mathrm{b}}$ & $145 \pm 45^{\mathrm{b}}$ \\
\hline Hyper-1 & $547 \pm 48^{\mathrm{a}}$ & $185 \pm 26^{\mathrm{b}}$ & \\
\hline \multicolumn{4}{|l|}{ Insulin (pmol/1) } \\
\hline Hyper-2/Hyper-3 & $187 \pm 40^{\mathrm{a}}$ & $630 \pm 68^{b}$ & $659 \pm 71^{\mathrm{b}}$ \\
\hline Hyper-1 & $126 \pm 19^{\mathrm{a}}$ & $542 \pm 21^{\mathrm{b}}$ & \\
\hline \multicolumn{4}{|l|}{ C-peptide (pmol/1) } \\
\hline Hyper-2/Hyper-3 & $1523 \pm 303^{\mathrm{a}}$ & $1602 \pm 279^{\mathrm{a}}$ & $1793 \pm 300^{\mathrm{b}}$ \\
\hline Hyper-1 & ND & ND & \\
\hline \multicolumn{4}{|l|}{ Glucagon (pmol/1) } \\
\hline Hyper-2/Hyper-3 & $36 \pm 6^{\mathrm{a}}$ & $32 \pm 6^{\mathrm{b}}$ & $46 \pm 9^{c}$ \\
\hline Hyper-1 & $30 \pm 5$ & $27 \pm 4$ & \\
\hline
\end{tabular}

significantly increased by $32 \%$, IAA by $53 \%$, BCAA by $64 \%$ and leucine by $100 \%$. Participants were hyperinsulinaemic at baseline, and insulin infusion markedly increased serum concentrations to postprandial targets during Hyper-1 and Hyper-2, without change in C-peptide in the latter. During Hyper-3, insulin concentrations achieved in Hyper- 2 were maintained by the $17 \%$ decrease in infusion rate, and C-peptide increased slightly (12\%) but significantly compared with baseline and Hyper-2 $(p=0.049)$. Compared with baseline, glucagon decreased slightly during Hyper-2 but not Hyper-1, while raising amino acids caused a $44 \%$ increase during Hyper-3 $(p<0.005)$. Serum NEFA were significantly suppressed by insulin during all three clamps to concentrations not different among protocols.
Leucine kinetics are presented in Fig. 2. The effect of hyperglycaemia on leucine kinetics was tested by comparing Hyper-2 ( $8 \mathrm{mmol} / \mathrm{l})$ with Hyper-1 (5.5 mmol/l) (Fig. 2a). Leucine flux (total $R_{\mathrm{a}}$ ), non-oxidative $R_{\mathrm{d}}$ (protein synthesis) and endogenous $R_{\mathrm{a}}$ (breakdown) were significantly higher in Hyper-2, but leucine oxidation and net balance $\left(R_{\mathrm{d}}-\right.$ endogenous $R_{\mathrm{a}}$ ) were not different. In neither clamp was the net balance anabolic.

During Hyper-3, amino acids were infused at a three- to fourfold increased rate to reach and maintain postprandial concentrations (Fig. 2b). Hyperaminoacidaemia caused significantly higher leucine flux and oxidation than during Hyper-2, synthesis increased by $17 \%(p<0.05)$ and breakdown decreased by $20 \%(p<0.005)$, which resulted in a 

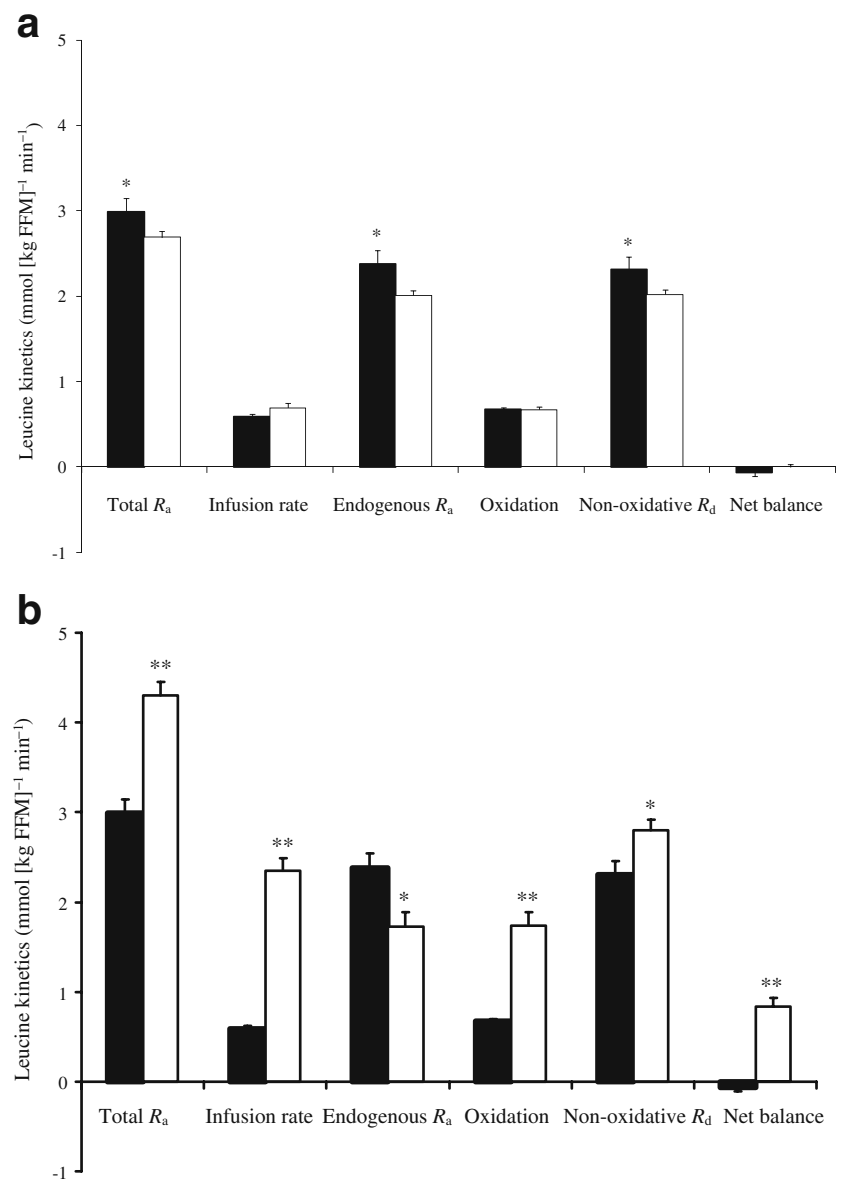

Fig. 2 Clamp whole body leucine kinetics in men with type 2 diabetes mellitus. Total $R_{\mathrm{a}}$, total leucine flux, including leucine infusion; endogenous $R_{\mathrm{a}}$, index of protein breakdown; non-oxidative $R_{\mathrm{d}}$, index of protein synthesis; net balance, synthesis minus breakdown. a Effect of hyperglycaemia during hyperinsulinaemia and isoaminoacidaemia in participants in this study, Hyper-2 $(8 \mathrm{mmol} / \mathrm{l})$ (black bars) vs Hyper-1 (5.5 mmol/l) (white bars) (data for eight participants from previous study [1]). Independent samples $t$ test; ${ }^{*} p=$ 0.05 . b Effect of hyperaminoacidaemia during hyperinsulinaemia and hyperglycaemia Hyper-2 (black bars) vs Hyper-3 (white bars); clamps performed sequentially in the same individuals. Paired $t$ test; ${ }^{*} p<0.01$ vs Hyper-2 clamp; ** $p<0.001$ vs Hyper- 2 clamp. Data are expressed per kg FFM

marked increase in net balance from $-5 \pm 3 \mu \mathrm{mol} / \mathrm{min}$ to $60 \pm 5 \mu \mathrm{mol} / \mathrm{min}(p<0.0001)$.

During Hyper-2, controlling for FFM, leucine flux correlated positively with markers of whole-body adiposity: weight ( $r=0.953, p=0.001)$, BMI $(r=0.853, p=0.015)$, fat mass $(r=0.953, p=0.001)$ and abdominal adiposity, inferred by waist circumference $(r=0.889, p=0.007)$. However, stepwise regression analysis showed that weight was the only independent variable that predicted $97 \%$ of the variance in flux such that when they were controlled for weight, correlations between flux and body composition were lost. However, controlling for body weight, net leucine balance was found to be negatively correlated with waist circum- ference $(r=-0.879, p=0.021)$. During Hyper-3, net leucine balance correlated negatively with $\log _{e}$ HOMA-IR $(r=$ $-0.745, p=0.034)$.

\section{Discussion}

This study showed a marked protein anabolic response to clamping insulin and amino acids at postprandial levels while maintaining the elevated fasting glucose at $8 \mathrm{mmol} / 1$ in type 2 diabetic men. This occurred despite evidence of insulin resistance of protein metabolism. Indeed the anabolic response to hyperinsulinaemia (Fig. 2a) was blunted to the same extent as when plasma glucose had been clamped at $5.5 \mathrm{mmol} / \mathrm{l}$ and amino acids at postabsorptive levels. It occurred at the 'cost' of accelerated protein turnover rates with glycaemia at $8 \mathrm{mmol} / 1$ [1]. The clinically pertinent implication is that physiological postprandial hyperaminoacidaemia can overcome such insulin resistance of protein anabolism in obese type 2 diabetic persons at a commonly observed level of hyperglycaemia.

The Hyper-3 phase of the clamp was designed to simulate a fed steady state, with target hyperglycaemia, hyperinsulinaemia and hyperaminoacidaemia at physiological postprandial concentrations of lean healthy individuals. This allowed for testing of one variable, increased amino acid provision, vs Hyper-2. It required that insulin be maintained at the same concentrations, and this was achieved by lowering its infusion rate to compensate for the anticipated increase in endogenous insulin secretion due to hyperaminoacidaemia $[22,31]$. This was confirmed by the slightly higher C-peptide concentrations. Thus, the unchanged peripheral serum insulin was the consequence of decreased exogenous and increased endogenous contributions. A decrease in hepatic insulin extraction as recently reported by Lan-Pidhainy and Wolever cannot be excluded [32]. Glucagon was also increased, though in the presence of 3.5-fold higher insulin the glucagonto-insulin ratio was minimally altered $(0.07 \pm 0.01$ vs $0.05 \pm$ 0.01 in Hyper-2).

The substantial increase in net protein balance with hyperaminoacidaemia was the result of both stimulated synthesis and suppressed breakdown (Fig. 2b). Leucine oxidation rate increased concurrently, consistent with greater protein contribution to energy expenditure compared with Hyper-2. If we assume that the thermic effect of the $25 \mathrm{~g}$ of protein administered is $105 \mathrm{~kJ}$ over $6 \mathrm{~h}(\sim 25 \%$ of energy content of the protein [33]), this matches the REE mean difference of $108 \mathrm{~kJ}$ over $6 \mathrm{~h}$ between Hyper- 2 and Hyper-3.

The marked increase in net balance in Hyper-3 prompted us to compare these leucine kinetic responses with those of eight healthy men (Fig. 3) from the group of nine previously studied [8]. They had lower BMI of $21.5 \pm 0.6 \mathrm{~kg} / \mathrm{m}^{2}$, age $29 \pm 3$ years, and FFM $59 \pm 2 \mathrm{~kg}$ (all $p<0.05$ vs the type 2 


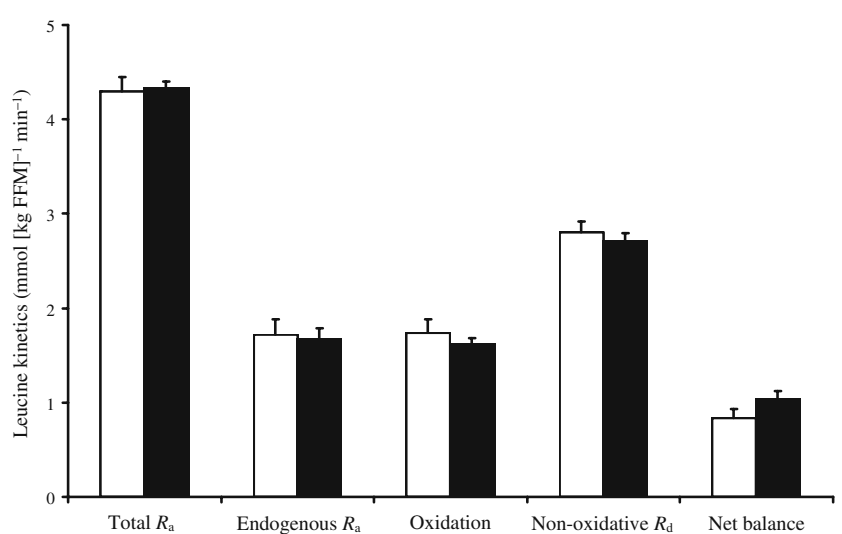

Fig. 3 Effect of type 2 diabetes on leucine kinetics during Hyper-3 clamps; type 2 diabetic men (white bars) vs lean non-diabetic men (black bars, adapted from Adegoke et al. [8] with permission from the American Physiological Society)

diabetic men in the present study). Their hyperglycaemia $(7.87 \pm 0.05 \mathrm{mmol} / \mathrm{l})$ and hyperaminoacidaemia (BCAA $709 \pm$ 24 , leucine $272 \pm 11$, TAA $3408 \pm 241$, IAA $1630 \pm 101 \mu \mathrm{mol} / \mathrm{l})$ did not differ from the participants with type 2 diabetes in the present study. However, hyperinsulinaemia was even greater ( $788 \pm 83 \mathrm{pmol} / \mathrm{l})$ because of a larger C-peptide response. Notwithstanding, none of the kinetic variables differed between groups, indicating the potency of amino acids themselves in the anabolic response. Interestingly, in lean non-diabetic individuals, the anabolic response was increased from a positive net leucine balance of 0.25 in Hyper-1 [26] to $0.99 \mu$ mol leucine $(\mathrm{kg} \mathrm{FFM})^{-1} \min ^{-1}$ in Hyper-3 [8], whereas in type 2 diabetes it reached the same levels in Hyper-3, but from zero net balance in Hyper-1/Hyper-2. This underscores the effectiveness of hyperaminoacidaemia in overcoming their insulin resistance of protein metabolism.

The 'normalised' protein kinetic response during Hyper-3 is consistent with results of Luzi et al. [17] and of Manders et al. [18], albeit with different participant characteristics. The latter reported that the muscle protein synthetic response in men with longstanding type 2 diabetes was not impaired after ingestion of carbohydrate and protein boluses. Our total amount of infused amino acids $(25 \mathrm{~g})$ was much less than the ingested protein (134 g) in Manders et al. [18]. We clamped BCAA at $770 \mu \mathrm{mol} / 1$ and most other amino acids at peak concentrations attained after mixed meal ingestion with $30 \mathrm{~g}$ protein in lean healthy individuals. However, we have reported lower peak postprandial amino acid concentrations $(\mathrm{BCAA}=650 \mathrm{pmol} / \mathrm{l})$ in poorly controlled type 2 diabetic men after consuming a similar meal [34]. Thus, it remains to be determined at what levels and durations of hyperaminoacidaemia protein kinetics become normalised in type 2 diabetes, as there could be a shift in 'doseresponse' to the right, requiring larger amounts of exogenous protein than the recommended requirements. Finally, despite normal mean anabolic response, net leucine balance during Hyper-3 was negatively correlated with an index of whole-body insulin resistance of glucose metabolism, $\log _{e}$ HOMA, supporting the notion that insulin resistance might still affect postprandial protein anabolism. Therefore, greater magnitudes of postprandial hyperaminoacidaemia in type 2 diabetes might increase protein synthesis and net protein anabolism to levels that could mask a persistent underlying insulin resistance of protein metabolism. Indeed, in the elderly, muscle protein synthesis in response to hyperaminoacidaemia and glucose-induced hyperinsulinaemia was found to be impaired [35], but was improved with an increased supply of amino acids [36]. Amino acids, particularly leucine, were shown to stimulate protein synthesis with and without elevated insulin [11, 12, 37, 38]. Leucine activates the mammalian target of rapamycin complex 1 (mTORC1) signalling $[39,40]$ by an as yet unclearly defined mechanism, but may involve Ras-related small GTP-binding proteins (RAG) that promote its intracellular perinuclear localisation, favouring its activation [41].

Our objective for the Hyper-2 clamp was to test the effect of insulin on protein metabolism in type 2 diabetes while maintaining 'usual' fasting hyperglycaemia and amino acid concentrations. Clamping glycaemia at $8.0 \mathrm{vs}$ $5.5 \mathrm{mmol} / \mathrm{l}$ was associated with significantly higher leucine flux, synthesis and breakdown rates, but those of leucine infusion, oxidation and net balance were not different (Fig. 2a). Such an effect has been reported in normal individuals, even at pharmacological hyperinsulinaemia [42]. Negative postabsorptive net balance [1] was brought only to equilibrium in both Hyper-1 and Hyper-2, in contrast to a positive balance in non-diabetic individuals $[1,26,42]$. Thus, in Hyper-2, the metabolic abnormality responsible for the hyperglycaemia was associated with blunted anabolism, with even greater 'inefficiency' in response to insulin, namely greater rates of turnover. This is consistent with our previous reports of accelerated integrated $24 \mathrm{~h}$ protein turnover rate in hyperglycaemic type 2 diabetes [43-46]. A factor in the greater leucine turnover in Hyper-2 might be the non-significant higher body weight and adiposity of Hyper-2 individuals, suggested by the strong correlation between these variables and leucine flux, and by weight being an independent determinant of turnover rate. Moreover, waist circumference (controlled for weight) was significantly and negatively correlated with net balance as previously demonstrated in obesity by us and others [1, 14, 47].

Some limitations of our protocol need to be considered. First, the simulated fed steady state does not mimic the temporal non-steady-state changes in substrate and hormone concentrations that occur during meal absorption. Second, Hyper-2 preceded Hyper-3 and thus the time of exposure to exogenous insulin and amino acids may have influenced the response to the second phase. Third, the 
amino acid composition of TrophAmine (Table 2) is different from that of usual food proteins, being particularly enriched in indispensable amino acids, particularly leucine. Thus, it remains to be shown whether similar findings, or magnitude of effects, would be seen with oral feeding.

This study has shown that, in overweight and obese men with type 2 diabetes, protein turnover is at an accelerated rate in hyperglycaemic clamps while insulin resistance of protein metabolism is of the same magnitude as found with euglycaemic clamps. Conversely, the whole-body protein anabolic response to postprandial hyperaminoacidaemia appears to be normal. Therefore, the postprandial protein anabolic capacity is preserved in type 2 diabetes in these conditions. Assuming constant kinetics, the mean net anabolism of $61 \mu \mathrm{mol} / \mathrm{min}$ in Hyper-3 would give an estimated $10 \mathrm{~g}$ protein over $3 \mathrm{~h}$, corresponding to the 'meal' with $25 \mathrm{~g}$ of amino acids contained in TrophAmine. This would restore one fourth of the postabsorptive net catabolism of $36 \mu \mathrm{mol} / \mathrm{min}$ [1], or $44 \mathrm{~g}$ endogenous proteins (based on $590 \mu \mathrm{mol}$ leucine/g protein [48]) over $12 \mathrm{~h}$ of overnight fast (also assuming constant catabolic rate). Thus by assuring ample protein intake, well distributed during the day, as in this protocol, type 2 diabetic individuals should be able to achieve $24 \mathrm{~h}$ protein equilibrium, even taking account of probable overestimation of the totals by such calculations. This could explain the paucity of evidence of clinical signs and abnormal standard clinical laboratory tests showing impaired protein metabolism in type 2 diabetes. These results do not, however, negate the fact that such equilibrium is at the cost of long-term abnormality ('inefficiency') of kinetics of protein metabolism, nor that a negative daily balance, too small to be detected by our methods, could lead to the accelerated muscle loss in type 2 diabetes, as recently shown $[2,3]$.

Acknowledgements This work was supported by a grant from Canadian Institutes of Health Research to R. Gougeon (MOP-77562) and salary awards to R. Gougeon, S. Pereira and M. Bassil from the McGill University Health Centre Research Institute, and to S. Chevalier and J. A. Morais from 'Fonds de recherche en santé du Québec'. We thank M. Shingler, C. Légaré, J. Plescia, K. French, I. Lalonde, M. Lamarche, D. White, G. Sabourin, C. Nardolillo and D. Brunetti for their assistance.

Duality of interest The authors declare that there is no duality of interest associated with this manuscript.

\section{References}

1. Pereira S, Marliss EB, Morais JA, Chevalier S, Gougeon R (2008) Insulin resistance of protein metabolism in type 2 diabetes. Diabetes 57:56-63

2. Park SW, Goodpaster BH, Lee JS et al (2009) Excessive loss of skeletal muscle mass in older adults with type 2 diabetes. Diabetes Care 32:1993-1997
3. Kim TN, Park MS, Yang SJ et al (2010) Prevalence and determinant factors of sarcopenia in patients with type 2 diabetes: The Korean Sarcopenic Obesity Study (KSOS). Diabetes Care 33:1497-1499

4. Jefferson LS, Koehler JO, Morgan HE (1972) Effect of insulin on protein synthesis in skeletal muscle of an isolated perfused preparation of rat hemicorpus. Proc Natl Acad Sci USA 69:816820

5. Nakano K, Hara H (1979) Insulin dependent and independent actions of dietary protein on in vitro protein synthesis in skeletal muscle of rats. J Nutr 109:1390-1398

6. Tessari P (1994) Effects of insulin on whole-body and regional amino acid metabolism. Diabetes Metab Rev 10:253-285

7. Tischler ME, Desautels M, Goldberg AL (1982) Does leucine, leucyl-tRNA, or some metabolite of leucine regulate protein synthesis and degradation in skeletal and cardiac muscle? J Biol Chem 257:1613-1621

8. Adegoke OAJ, Chevalier S, Morais JA et al (2009) Fed-state clamp stimulates cellular mechanisms of muscle protein anabolism and modulates glucose disposal in normal men. Am J Physiol Endocrinol Metab 296:E105-E113

9. Bennet WM, Connacher AA, Scrimgeour CM, Jung RT, Rennie MJ (1990) Euglycemic hyperinsulinemia augments amino acid uptake by human leg tissues during hyperaminoacidemia. Am J Physiol Endocrinol Metab 259:E185-E194

10. Hillier TA, Fryburg DA, Jahn LA, Barrett EJ (1998) Extreme hyperinsulinemia unmasks insulin's effect to stimulate protein synthesis in the human forearm. Am J Physiol Endocrinol Metab 274:E1067-E1074

11. Castellino P, Luzi L, Simonson DC, Haymond M, DeFronzo RA (1987) Effect of insulin and plasma amino acid concentrations on leucine metabolism in man. Role of substrate availability on estimates of whole body protein synthesis. J Clin Invest 80:1784 1793

12. Tessari P, Inchiostro S, Biolo G et al (1987) Differential effects of hyperinsulinemia and hyperaminoacidemia on leucine-carbon metabolism in vivo. Evidence for distinct mechanisms in regulation of net amino acid deposition. J Clin Invest 79:10621069

13. Nygren J, Nair KS (2003) Differential regulation of protein dynamics in splanchnic and skeletal muscle beds by insulin and amino acids in healthy human subjects. Diabetes 52:1377-1385

14. Chevalier S, Marliss EB, Morais JA, Lamarche M, Gougeon R (2005) Whole-body protein anabolic response is resistant to the action of insulin in obese women. Am J Clin Nutr 82:355-365

15. Denne SC, Brechtel G, Johnson A, Liechty EA, Baron AD (1995) Skeletal muscle proteolysis is reduced in noninsulin-dependent diabetes mellitus and is unaltered by euglycemic hyperinsulinemia or intensive insulin therapy. J Clin Endocrinol Metab 80:23712377

16. Halvatsiotis PG, Turk D, Alzaid A, Dinneen S, Rizza RA, Nair KS (2002) Insulin effect on leucine kinetics in type 2 diabetes mellitus. Diabetes Nutr Metab 15:136-142

17. Luzi L, Petrides AS, de Fronzo RA (1993) Different sensitivity of glucose and amino acid metabolism to insulin in NIDDM. Diabetes 42:1868-1877

18. Manders RJ, Koopman R, Beelen M et al (2008) The muscle protein synthetic response to carbohydrate and protein ingestion is not impaired in men with longstanding type 2 diabetes. J Nutr 138:1079-1085

19. Bassil M, Marliss EB, Morais JA, Gougeon R (2009) Net protein anabolic response is not altered during hyperaminoacidemic (hyperAA) clamp in men with Type 2 Diabetes (T2D). FASEB J 23:1

20. (1997) The MONICA Optional Study of Physical Activity (MOSPA). Med Sci Sports Exerc 29:162-169 
21. Zello GA, Smith JM, Pencharz PB, Oball R (1990) Development of a heating device for sampling arterialized venous blood from a hand vein. Ann Clin Biochem 27:366-372

22. Nuttall FQ, Gannon MC (1991) Plasma glucose and insulin response to macronutrients in nondiabetic and NIDDM subjects. Diabetes Care 14:824-838

23. Matthews DE, Motil KJ, Rohrbaugh DK, Burke JF, Young VR, Bier DM (1980) Measurement of leucine metabolism in man from a primed, continuous infusion of L- $\left[1-{ }^{13} \mathrm{C}\right]$ leucine. Am J Physiol 238:E473-E479

24. Matthews DE, Schwarz HP, Yang RD, Motil KJ, Young VR, Bier DM (1982) Relationship of plasma leucine and alpha-ketoisocaproate during a L- $\left[1-{ }^{13} \mathrm{C}\right]$ leucine infusion in man: a method for measuring human intracellular leucine tracer enrichment. Metabolism 31:11051112

25. Cynober LA (ed) (1995) Amino acid metabolism and therapy in health and nutritional disease. CRC Press, Boca Raton

26. Chevalier S, Gougeon R, Kreisman SH, Cassis C, Morais JA (2004) The hyperinsulinemic amino acid clamp increases wholebody protein synthesis in young subjects. Metabolism 53:388-396

27. Chevalier S, Marliss EB, Morais JA, Lamarche M, Gougeon R (2005) The influence of sex on the protein anabolic response to insulin. Metabolism 54:1529-1535

28. Chevalier S, Burgess SC, Malloy CR, Gougeon R, Marliss EB, Morais JA (2006) The greater contribution of gluconeogenesis to glucose production in obesity is related to increased whole-body protein catabolism. Diabetes 55:675-681

29. Lachin JM (1981) Introduction to sample size determination and power analysis for clinical trials. Control Clin Trials 2:93-113

30. World Health Organization (2000) Obesity: preventing and managing the global epidemic. Report of a WHO consultation. The Organization, Geneva

31. Manders RJF, Wagenmakers AJM, Koopman R et al (2005) Coingestion of a protein hydrolysate and amino acid mixture with carbohydrate improves plasma glucose disposal in patients with type 2 diabetes. Am J Clin Nutr 82:76-83

32. Lan-Pidhainy X, Wolever TM (2010) The hypoglycemic effect of fat and protein is not attenuated by insulin resistance. Am J Clin Nutr 91:98-105

33. Gougeon R (2001) Effect of insulin and energy restriction on the thermic effect of protein in type 2 diabetes mellitus. Obes Res 9:241-250

34. Mourad C, Chevalier S, Morais JA, Lamarche M, Gougeon R (2009) Antihyperglycaemic medication modifies factors of postprandial satiety in type 2 diabetes. Diabetes Obes Metab 11:819-822
35. Volpi E, Mittendorfer B, Rasmussen BB, Wolfe RR (2000) The response of muscle protein anabolism to combined hyperaminoacidemia and glucose-induced hyperinsulinemia is impaired in the elderly. J Clin Endocrinol Metab 85:4481-4490

36. Volpi E, Ferrando AA, Yeckel CW, Tipton KD, Wolfe RR (1998) Exogenous amino acids stimulate net muscle protein synthesis in the elderly. J Clin Invest 101:2000-2007

37. Buse MG, Reid SS (1975) Leucine. A possible regulator of protein turnover in muscle. J Clin Invest 56:1250-1261

38. Anthony JC, Anthony TG, Layman DK (1999) Leucine supplementation enhances skeletal muscle recovery in rats following exercise. J Nutr 129:1102-1106

39. Kim D-H, Sarbassov DD, Ali SM et al (2002) mTOR interacts with raptor to form a nutrient-sensitive complex that signals to the cell growth machinery. Cell 110:163-175

40. Kimball SR, Shantz LM, Horetsky RL, Jefferson LS (1999) Leucine regulates translation of specific mRNAs in L6 myoblasts through mTOR-mediated changes in availability of eIF4E and phosphorylation of ribosomal protein S6. J Biol Chem 274:1164711652

41. Sancak Y, Peterson TR, Shaul YD et al (2008) The rag GTPases bind raptor and mediate amino acid signaling to mTORC1. Science 320:1496-1501

42. Flakoll PJ, Hill JO, Abumrad NN (1993) Acute hyperglycemia enhances proteolysis in normal man. Am J Physiol 265:E715E721

43. Gougeon R, Styhler K, Morais JA, Jones PJ, Marliss EB (2000) Effects of oral hypoglycemic agents and diet on protein metabolism in type 2 diabetes. Diabetes Care 23:1-8

44. Gougeon R, Pencharz PB, Sigal RJ (1997) Effect of glycemic control on the kinetics of whole-body protein metabolism in obese subjects with non-insulin-dependent diabetes mellitus during isoand hypoenergetic feeding. Am J Clin Nutr 65:861-870

45. Gougeon R, Pencharz PB, Marliss EB (1994) Effect of NIDDM on the kinetics of whole-body protein metabolism. Diabetes 43: 318-328

46. Gougeon R, Morais JA, Pencharz PB, Jones PJ, Marliss E (1997) Oral agents and insulin improve the abnormalities in protein turnover in proportion to glycemic improvement in obese type 2 diabetic subjects. Int J Obes (Suppl 2):S108

47. Luzi L, Castellino P, DeFronzo RA (1996) Insulin and hyperaminoacidemia regulate by a different mechanism leucine turnover and oxidation in obesity. Am J Physiol 270:E273-E281

48. Wolfe R (1992) Radioactive and stable isotope tracers in biomedicine. Wiley, New York 